\title{
Acceptance and Commitment Therapy, Selective Serotonin Reuptake Inhibitors, and Their Combination in the Improvement of Obsessive- Compulsive Symptoms and Experiential Avoidance in Patients With Obsessive-Compulsive Disorder
}

\author{
Yaghoob Vakili ${ }^{1, *} ;$ Banafsheh Gharaee $^{2} ;$ Mojtaba Habibi $^{3}$ \\ ${ }_{1}^{1}$ Department of Clinical Psychology, School of Medicine, North Khorasan University of Medical Sciences, Bojnord, IR Iran \\ ${ }_{3}^{2}$ Department of Clinical Psychology, Tehran Psychiatric Institute, Iran University of Medical Sciences, Tehran, IR Iran \\ ${ }^{3}$ Departments of Family Therapy, Family Research Institute, University of Shahid Beheshty, Tehran, IR Iran \\ ${ }^{*}$ Corresponding author: Yaghoob Vakili, Department of Clinical Psychology, School of Medicine, North Khorasan University of Medical Sciences, Bojnord, IR Iran. Tel: +98-9366644146, \\ Fax:+98-5842296764, E-mail: yaghoobvakili@yahoo.com
}

Received: December 20, 2013; Revised: June 20, 2014; Accepted: September 5, 2014

\begin{abstract}
Background: Selective serotonin reuptake inhibitors (SSRIs) and exposure with response prevention for treatment of obsessivecompulsive disorder (OCD) have demonstrated empirical support; however, a substantial number of patients remain with clinically significant OCD symptoms after such treatments.

Objectives: The aim of this study was to compare the effectiveness of acceptance and commitment therapy (ACT), selective serotonin reuptake inhibitors (SSRIs) and combination of ACT and SSRIs in the treatment of adults with obsessive-compulsive disorder (OCD).

Patients and Methods: Thirty-two outpatients meeting Diagnostic and Statistical Manual of Mental Disorders, Fourth Edition, Text Revision criteria for OCD were randomly assigned to one of the three treatment conditions: ACT, SSRIs and combined treatment. The YaleBrown Obsessive-Compulsive Scale and Acceptance and Action Questionnaire were administered at pre-treatment and post-treatment. Twenty-seven patients completed the study. Data was analyzed using one-way analysis of variance (ANOVA) and one-way analysis of covariance (ANCOVA), clinically significant change (CSC) and complete remission status.

Results: ANCOVA revealed that patients treated with ACT and combined treatment experienced a significantly greater improvement in obsessive-compulsive (OC) symptoms and experiential avoidance (EA) at post-treatment compared to those treated with SSRIs alone. However, there were no significant differences between ACT and combined treatment on OC symptoms and EA. CSC and complete remission status results showed that unlike SSRI, ACT and combined treatment led to more improvement in OC symptoms.

Conclusions: ACT and combined treatment are more effective than SSRIs alone in treating OC symptoms and EA. However, it appears that adding SSRIs to ACT does not increase the effectiveness of ACT in the treatment of adults with OCD in the short-term.
\end{abstract}

Keywords: Acceptance and Commitment Therapy; Obsessive-Compulsive Disorder; Selective Serotonin Reuptake Inhibitors

\section{Background}

Selective serotonin reuptake inhibitors (SSRIs) and exposure with response prevention for treatment of obsessive-compulsive disorder (OCD) have demonstrated empirical support; however, a substantial number of patients remain with clinically significant OCD symptoms after these treatments (1-6). In recent years, one of the promising novel treatment strategies developed to improve the efficacy of treatment for patients with OCD is acceptance and commitment therapy $(\mathrm{ACT})(7,8)$. ACT is a third-wave behavior therapy, which specifically focuses on decreasing experiential avoidance (EA), increasing activity in the chosen valued life direction and increasing psychological flexibility. The goal of ACT is not symptom reduction per se, but helping patients to accept aversive inner experiences (e.g. thoughts, images, emotions and bodily sensations) in the service of engaging in valuesguided behavior (9).

EA is defined as unwillingness to remain in contact or experience aversive private thoughts or experiences to avoid or escape from these experiences (7). EA has been suggested to play an important role in the development and maintenance of OCD (10). EA has been hypothesized to manifest as compulsions in OCD (10). In EA perspective, patients with OCD engage in compulsions to control or reduce their unwanted obsessional thoughts, because they want to reduce negative affect associated with them (10). In support of this perspective, correlational studies have found that high levels of EA were positively associated with high levels obsessive-compulsive (OC) symptoms (11-13). In treating OCD, ACT targets EA and cognitive fusion through "defusion" and acceptance techniques. ACT teaches patients to create a new relationship with obsessive thoughts and anxious emotions, for example, helping patients notice that a thought is just thought and anxiety is an emotion to be felt. ACT also helps patients commit to act in the service of their valued life

Copyright (C) 2015, Mazandaran University of Medical Sciences. This is an open-access article distributed under the terms of the Creative Commons Attribution-NonCommercial 4.0 International License (http://creativecommons.org/licenses/by-nc/4.0/) which permits copy and redistribute the material just in noncommercial usages, provided the original work is properly cited. 
goals rather than spending large amounts of time trying to decrease the obsession or avoid anxious feelings. ACT helps patients to accept their obsessional thoughts and negative feelings and commit to acting in service of their valued life directions whether obsessions were occurring. Thus, these constructs would increase psychological flexibility, which is the ability to act inconsistent with patient's meaningful life directions regardless of unpleasant inner experiences $(14,15)$.

ACT has demonstrated large and clinically significant improvements in OCD symptoms in adults (14-17) and adolescent (18). However, according to the best of our knowledge, there are no randomized controlled studies directly comparing the relative effectiveness of ACT with SSRIs and combination of ACT and SSRIs in the treatment of OCD.

\section{Objectives}

Therefore, the aim of this study was to compare ACT with SSRIs and combination of ACT and SSRIs in improvement of OC symptoms and EA.

\section{Materials and Methods}

In an experimental design using convenience sampling, adults with OCD were recruited from outpatients of clinics in Tehran, Iran, from February 2012 to March 2013. The study was approved by the Ethics Committee of Tehran University of Medical Sciences. A written informed consent was obtained from patients and received complete descriptions regarding the study procedures. Inclusion criteria for the sample were: a) a primary diagnosis of OCD according to the Diagnostic and Statistical Manual of Mental Disorders, Fourth Edition, Text Revision (DSM-IV-TR) (19); b) age between 18 and 50 years; and c) OC symptoms duration of at least one year. Patients were excluded from the study if they: a) had a current or past psychotic disorder; b) had suicidal tendencies; c) had a medical illness; d) had a substance abuse disorder; e) had a personality disorder and f) had been treated with either pharmacotherapy or psychotherapy in the last one month. Forty-four patients were referred for treatment, of which 40 met the DSM-IV-TR criteria for OCD. They were interviewed by a structured clinical interview for DSM-IV axis I disorders, patient edition (SCID-I/P version 2) (20) and a structured clinical interview for DSM-IV axis II disorders (SCID-II) (21) to verify the diagnosis by an independent evaluator (PhD level clinical psychologist). Two patients with bipolar disorder, two patients with psychotic disorder, one patient with avoidant personality disorder, two patients with OC personality disorder and one patient with borderline personality disorder were excluded from the study. In all, 32 patients fitted the inclusion/exclusion criteria and were randomly assigned to receive ACT $(n=10)$, SSRIs ( $n=$ 11) or combination of ACT and SSRIs $(n=11)$. Five patients did not complete the study. Three patients dropped out the drug group; one because of not tolerating adverse effects of sertraline and two for irregular use of fluoxetine. One patient abandoned the ACT group for needing SSRI during the treatment phase. One patient dropped out of the combination group for unknown reasons.

The mean age of the final sample $(n=27)$ was $26.96 \pm 6.83$ years; $55.6 \%(n=15)$ of the patients were men and $44.4 \%(n$ $=12$ ) women. Duration of OC symptoms ranged between 1 and 16 years. The Yale-Brown Obsessive-Compulsive Scale (Y-BOCS) total and Acceptance and Action Questionnaire (AAQ) scores (mean \pm standard deviation) for the sample were $24.40 \pm 3.07$ and $36.20 \pm 6.08$, respectively. All patients met the criteria for OCD as their primary diagnosis with $33.3 \%$ receiving one additional diagnosis. The frequency of comorbidities in each treatment condition was as follows; major depressive disorder and dysthymia, two ACT, two SSRIs, two ACT plus SSRIs; anxiety disorders, one ACT, one SSRI, one ACT plus SSRIs. OCD subtypes for the sample were washing, checking, ordering, religious/sexual/aggressive thoughts and hoarding.

ACT was based on an ACT manual for OCD developed by Twohig (14). A PhD clinical psychologist (the first author) provided ACT under the supervision of an experienced clinical psychologist in treating OCD. The ACT program included evaluating patient's obsessions and compulsions (session 1); The "Man in the hole" metaphor was used to illustrate how patient's efforts to regulate obsessions are ineffective (session 2); The "Tow scales" metaphor was used to illustrate possible benefits of acceptance of obsessions and anxiety rather than attempting to control or reduce them (sessions 3 and 4); using defusion, contact with present or mindfulness, and self as context exercises (sessions 5 and 6 ); recognize his values; and preventing relapse (sessions 7 and 8). Patients in drug group received a different SSRI (sertraline $=50-200 \mathrm{mg} / \mathrm{d}$; fluoxetine $=20-80 \mathrm{mg} / \mathrm{d}$ ) for 10 weeks, which was monitored by two psychiatrists. The combination group received both ACT and a different SSRI (sertraline $=50-200 \mathrm{mg} / \mathrm{d}$; fluoxetine $=20-80 \mathrm{mg} / \mathrm{d}$ ) for 10 weeks. Studies showed equivalent efficacy for different SSRIs in OCD (2). In this study, we did not compare the efficacy of sertraline with fluoxetine on each outcome measure at the end of treatment.

SCID-I/P and SCID-II are widely used as gold standard instruments for diagnosing axis I and axis II disorders (22). All participants were initially assessed using the SCID-I/P and SCID-II. Clinical symptoms were assessed using the Y-BOCS $(23,24), \mathrm{AAQ}(25)$ at the beginning and end of treatment.

Y-BOCS is a 10-item clinician administered scale used for the assessment of severity of OC symptoms. It has good psychometric properties and has shown excellent treatment sensitivity $(23,24,26,27)$. AAQ is a 9-item self-report scale, which assesses EA. Each item is rated on a 7-point scale with higher scores indicating greater EA (range: 7 - 63). It has demonstrated good internal consistency ( $\alpha=0.70)$ and test-retest reliability over a 4-month interval ( $\mathrm{rs}=0.64)(24)$. The reliability and validity of the Iranian version of the YBOCS (28), AAQ (29), SCID-I/P and SCID-II (30) have been evaluated and shown to be as good as their original versions. 
Vakili Y et al.

The criteria for clinically significant change (CSC) considered a Y-BOCS total score reduction of eight scores or more from pre-treatment to post-treatment and a final YBOCS total score $\leq 14$. Patients who achieved CSC were defined as recovered. Patients were classified as improved if they achieved reliable change that is eight score or more, but scoring above 14 on Y-BOCS total. Patients who did not achieve reliable change on the Y-BOCS were defined as unchanged (6). Full remission was defined as posttreatment Y-BOCS total score $\leq 8$ (31).

Group differences were evaluated using chi-square, oneway analysis of variance (ANOVA) and one-way analysis of covariance (ANCOVA) statistical procedures on each of the outcome measures using SPSS for Windows (version 16.0, SPSS Inc., Chicago, IL, USA) statistical package.

\section{Results}

Using ANOVA and chi-square test, no significant difference was found between the groups regarding demographic characteristics and pre-treatment measures (Tables 1 and 2).

\subsection{CSC}

Patients achieving CSC at post-treatment were 44.4\%, $40.0 \%$ and $12.5 \%$ for ACT, combined and SSRIs groups, respectively. Two patients (22.2\%) in ACT and two patients (20.0\%) in combined group and two patients (25.0\%) in SSRIs group met the criteria for reliability improved. Three patients (33.3\%) in ACT, four patients (40.0\%) in combined and five patients (62.5\%) in SSRIs groups were classified as unchanged.

\begin{tabular}{|c|c|c|c|c|}
\hline \multirow[t]{2}{*}{ Measure } & \multicolumn{3}{|c|}{ Group } & \multirow{2}{*}{$\begin{array}{l}\chi^{2} \text { and } \mathbf{F} \\
\text { Statistic }\end{array}$} \\
\hline & ACT & SSRIs & Combined & \\
\hline $\begin{array}{l}\text { Proportion men/ } \\
\text { woman }\end{array}$ & $5 / 4$ & $4 / 4$ & $6 / 4$ & $\chi^{2}=0.18$ \\
\hline $\begin{array}{l}\text { Proportion } \\
\text { single/married }\end{array}$ & $4 / 5$ & $4 / 4$ & $5 / 5$ & $\chi^{2}=0.08$ \\
\hline Age, y & $25.89 \pm 5.58$ & $27.13 \pm 4.48$ & $27.80 \pm 9.46$ & $F=0.17$ \\
\hline Education, y & $14.33 \pm 1.32$ & $13.12 \pm 2.29$ & $14.20 \pm 1.81$ & $\mathrm{~F}=1.10$ \\
\hline OCD duration, y & $5.22 \pm 1.85$ & $5.63 \pm 2.67$ & $6.20 \pm 4.44$ & $\mathrm{~F}=0.22$ \\
\hline \multicolumn{5}{|c|}{$\begin{array}{l}\text { a Abbreviations: ACT, Acceptance and commitment therapy; OCD, } \\
\text { Obsessive-compulsive disorder; and SSRIs, Selective serotonin reuptake } \\
\text { inhibitors. } \\
\text { b Data are presented as Mean } \pm \text { SD, and all P >0.001. }\end{array}$} \\
\hline
\end{tabular}

\begin{tabular}{|c|c|c|c|c|}
\hline \multirow[t]{2}{*}{ Measure } & \multicolumn{3}{|c|}{ Group } & \multirow[t]{2}{*}{ F Statistic } \\
\hline & ACT & SSRIS & Combined & \\
\hline Y-BOCS & $23.86 \pm 2.57$ & $25.63 \pm 2.44$ & $24.10 \pm 3.69$ & 0.76 \\
\hline AAQ & $34.89 \pm 6.71$ & $38.25 \pm 5.54$ & $35.80 \pm 5.88$ & 0.68 \\
\hline $\begin{array}{l}\text { a Abbrev } \\
\text { Acceptance } \\
\text { inhibitors; } \\
\text { b Data are }\end{array}$ & $\begin{array}{l}\text { tions: AAQ, A } \\
\text { d commitmen } \\
\text { d Y-BOCS, Yale- }\end{array}$ & $\begin{array}{l}\text { ceptance and } \\
\text { t therapy; SSRI } \\
\text { 3rown Obsessiv }\end{array}$ & $\begin{array}{l}\text { Action Questi } \\
\text { Selective serot } \\
\text {-Compulsive Sc } \\
>0.001 \text {. }\end{array}$ & $\begin{array}{l}\text { onnaire; ACT, } \\
\text { onin reuptake } \\
\text { ale. }\end{array}$ \\
\hline
\end{tabular}

\subsection{Full Remission}

Regarding the criteria for OC symptoms full remission (Y-BOCS score $\leq 8$ ), two patients $(22.2 \%)$ in ACT and two patients $(20.0 \%)$ in combined group achieved this improvement level, but none of the patients in SSRIs group had full remission.

\subsection{ANCOVA Results}

Table 3 displays the mean scores, standard deviation and ANCOVA results on each outcome measure at the end of treatment. The assumptions of homogeneity of variance and homogeneity of regression were met for each of the comparisons. ANCOVA results revealed significant differences between the groups on Y-BOCS and AAQ. Pair-wise post-hoc comparisons of the means of the groups showed significant differences between ACT and SSRIs as well as between combined treatment and SSRIs on the Y-BOCS and AAQ at post-treatment. However, there were no significant differences between ACT and combined treatment on the measures. Effect sizes using Cohen's d (difference between adjusted means divided by the pooled standard deviation (32) was calculated to evaluate the size of differences between the treatment groups. Large effect sizes were found for differences between the ACT group and the SSRI group as well as between the combined group and the SSRI group on the Y-BOCS and AAQ. However, there were no significant differences between ACT and combined groups on OC symptoms and EA at post-treatment (Table 4).

Table 3. Post-Treatment Outcome Measures, Analysis of Covariance (Using the Pre-Treatment Scores as the Covariate) ${ }^{a, b}$

\begin{tabular}{|c|c|c|c|c|}
\hline \multirow[t]{2}{*}{ Measure } & \multicolumn{3}{|c|}{ Group } & \multirow[t]{2}{*}{ F Statistic } \\
\hline & ACT & SSRIS & Combined & \\
\hline Y-BOCS & $14.00 \pm 4.55$ & $19.88 \pm 3.68$ & $13.80 \pm 3.85$ & 05.03 \\
\hline AAQ & $23.33 \pm 5.95$ & $33.50 \pm 6.37$ & $23.20 \pm 5.32$ & 12.46 \\
\hline $\begin{array}{l}\text { a Abbrev } \\
\text { Acceptance } \\
\text { inhibitors; } \\
\text { b Data are }\end{array}$ & $\begin{array}{l}\text { ions: AAQ, A } \\
\text { d commitmer } \\
\text { d Y-BOCS, Yale- }\end{array}$ & $\begin{array}{l}\text { eptance and } \\
\text { therapy; SSRI } \\
\text { rown Obsessi }\end{array}$ & $\begin{array}{l}\text { Action Quest } \\
\text { Selective serot } \\
\text { e-Compulsive }\end{array}$ & $\begin{array}{l}\text { nnaire; ACT, } \\
\text { nin reuptake } \\
\text { ale. }\end{array}$ \\
\hline
\end{tabular}

\begin{tabular}{lccc}
\hline \multicolumn{4}{l}{ Table 4. Effect Sizes for Pairwise Post-Hoc Comparisons ${ }^{\mathrm{a}, \mathrm{b}}$} \\
\hline Measure & ACT vs. SSRIs & ACT vs. Combined & $\begin{array}{c}\text { Combined } \\
\text { vs. SSRIs }\end{array}$ \\
\hline Y-BOCS & $1.14^{\mathrm{C}}$ & 0.07 & $1.28^{\mathrm{C}}$ \\
AAQ & $1.18^{\mathrm{C}}$ & 0.14 & $1.35^{\mathrm{C}}$ \\
\hline
\end{tabular}

a Abbreviations: AAQ, Acceptance and Action Questionnaire; ACT, Acceptance and commitment therapy; SSRIs, Selective serotonin reuptake inhibitors; and Y-BOCS, Yale-Brown Obsessive-Compulsive Scale.

b $\mathrm{d}=$ Cohen's effect size $(0.2=$ small effect, $0.5=$ medium effect, $0.8=$ large effect).

C $\mathrm{P}<0.001$. 


\section{Discussion}

All three treatments were effective in reducing total scores in the Y-BOCS and AAQ at post-treatment. Nevertheless, ACT and combined treatment presented significantly greater improvements in severity of OC symptoms and EA and a higher rate of complete remission of OC symptoms than those resulting from SSRIs use. Furthermore, ACT and combined treatment produced greater rates of recovery in OC symptoms compared to SSRIs alone.

Regarding OC symptoms improvement, our results were similar to those found in previous studies with ACT (1418 ) and SSRIs $(1,2)$. The rate of reduction in the Y-BOCS in the study of Twohig et al. (15), was $47.3 \%$ at post-treatment, which is virtually the same as $41.3 \%$ reduction at the end of ACT observed in the current study. A possible explanation for the effectiveness of ACT may be the fact that reductions in EA and cognitive fusion produce greater psychological flexibility. ACT aimed at helping patients to accept their obsessional thoughts and negative feelings and commit to acting in service of their valued life goals regardless of obsessions were occurring. Increasing psychological flexibility and values-based action in the presence of obsessional thoughts and negative emotions could be a core process of change in OC symptoms (15). In support of this perspective, evidence (14-18) show that reduction in OC symptoms is due to specific processes used in ACT (i.e. acceptance and cognitive defusion). ACT processes (e.g. reductions in EA) changed prior to changes in OCD severity. In the present study, EA decreased in ACT and combined treatment groups, without significant difference between the groups. These results are inconsistent with studies of Twohig (14), Twohig et al. (15,16) and Armstrong (18), which demonstrated reductions in EA in patients with OCD following ACT. From an ACT perspective, increasing one's willingness to experience obsessional thoughts and negative feelings and not engage in behaviors to decrease them produces reductions in EA and compulsions (15).

The finding that ACT is more effective in improving OC symptoms than SSRIs is consistent with previous findings by Foa et al. (33), Sousa et al. (31), Abramowitz et al. (34) and Shareh et al. (35) who found the superiority of psychotherapy over anti-obsessive drugs alone in the treatment of adults with OCD. Similarly, Foa et al. (33), Shareh et al. (35) and Giasuddin et al. (36) observed that the combination of psychotherapy and pharmacotherapy reached better results than pharmacotherapy alone.

Eddy et al. (3) by reviewing 18 randomized controlled trials found that the combination treatment is more effective in reducing OC symptoms than either psychotherapy or medication alone. However, in the present study, the combined treatment was only more effective in reducing total scores in the Y-BOCS than medication alone. In this study, no significant differences were found between ACT and combined treatment regarding the OC symptoms improvement. These findings support the results of two studies $(37,38)$, which found no advantages of combining med- ication and psychotherapy compared to psychotherapy alone in treating patients with OCD, although, unlike the present study, these studies found no significant differences between combined treatment and medication alone.

The results of the present study demonstrated that combining SSRIs with ACT does not increase the effectiveness of ACT in improving OC symptoms and EA in patients with OCD in short-time. Moreover, patients treated with ACT and combined treatment experienced further improvement in OC symptoms and EA at post-treatment compared to those treated with SSRIs alone.

This study had several limitations. The sample size was small, and thus, these findings should be considered preliminary until replicated in larger sample sizes. Further researches are necessary to examine whether our results are applicable to patients with OCD and other comorbid conditions excluded from this study. The present study did not have a follow-up assessment. Therefore, future research is needed to evaluate long-term effects of all three mentioned treatments for OCD. It is recommended to perform further studies to compare the effectiveness of ACT with other empirically supported treatments and combination of these treatments with SSRIs for OCD. Despite these limitations, our results provided supporting evidence for effectiveness of ACT in helping patients with OCD to experience significant improvements in EA and OC symptoms, as well highlighted the importance and need for additional studies in this area.

\section{Acknowledgements}

The study was approved by the Ethics Committee of Tehran University of Medical Sciences (The code of ethics: 60101179621210291). We also thank Dr. Mehriar NadrMohammadi for evaluating patients.

\section{Authors' Contributions}

Yaghoob Vakili conceived and designed the evaluation, collected clinical data, interpreted them, performed statistical analysis, drafted the manuscript and revised it. Banafsheh Gharaee participated in designing the evaluation and helped to draft and revised the manuscript. Mojtaba Habibi participated in designing the evaluation, interpretation of clinical data, statistical analysis, drafting and revising the manuscript. All authors read and approved the final manuscript.

\section{Clinical Trial Registration Code}

2013042713145 N1.

\section{Ethics Committee Code}

60101179621210291.

\section{Funding/Support}

We thank the Medical Research Council of Tehran Uni- 
versity of Medical Sciences for providing financial support for this research.

\section{Declaration of Interest}

None declared.

\section{References}

1. Bandelow B, Zohar J, Hollander E, Kasper S, Moller HJ, Wfsbp Task Force on Treatment Guidelines for Anxiety O, et al. World Federation of Societies of Biological Psychiatry (WFSBP) guidelines for the pharmacological treatment of anxiety, obsessive-compulsive and post-traumatic stress disorders - first revision. World J Biol Psychiatry. 2008;9(4):248-312.

2. Koran LM, Hanna GL, Hollander E, Nestadt G, Simpson HB, American Psychiatric A. Practice guideline for the treatment of patients with obsessive-compulsive disorder. Am J Psychiatry. 2007;164(7 Suppl):5-53.

3. Eddy KT, Dutra L, Bradley R, Westen D. A multidimensional metaanalysis of psychotherapy and pharmacotherapy for obsessivecompulsive disorder. Clin Psychol Rev. 2004;24(8):1011-30.

4. Rosa-Alcazar AI, Sanchez-Meca J, Gomez-Conesa A, Marin-Martinez F. Psychological treatment of obsessive-compulsive disorder: a meta-analysis. Clin Psychol Rev. 2008;28(8):1310-25.

5. Greist JH, Jefferson JW, Kobak KA, Katzelnick DJ, Serlin RC. Efficacy and tolerability of serotonin transport inhibitors in obsessive-compulsive disorder. A meta-analysis. Arch Gen Psychiatry. 1995;52(1):53-60.

6. Fisher PL, Wells A. How effective are cognitive and behavioral treatments for obsessive-compulsive disorder? A clinical significance analysis. Behav Res Ther. 2005;43(12):1543-58.

7. Hayes SC, Strosahl K, Wilson KG. Acceptance and Commitment Therapy: An Experiential Approach to Behavior Change.New York: Guilford Press; 2003.

8. Hayes SC, Strosahl KD, Wilson KG. Acceptance and Commitment Therapy, Second Edition: The Process and Practice of Mindful Change.New York: Guilford Publications; 2011.

9. Hayes SC. Acceptance and commitment therapy, relational frame theory, and the third wave of behavioral and cognitive therapies. Behavi Ther. 2004;35(4):639-65.

10. Eifert GH, Forsyth JP. Acceptance \& Commitment Therapy for Anxiety Disorders: A Practitioner's Treatment Guide to Using Mindfulness, Acceptance, and Values-based Behavior Change Strategies.Oakland: New Harbinger Publications; 2005.

11. Abramowitz JS, Lackey GR, Wheaton MG. Obsessive-compulsive symptoms: the contribution of obsessional beliefs and experiential avoidance. J Anxiety Disord. 2009;23(2):160-6.

12. Briggs ES, Price IR. The relationship between adverse childhood experience and obsessive-compulsive symptoms and beliefs: the role of anxiety, depression, and experiential avoidance. J Anxiety Disord. 2009;23(8):1037-46.

13. Wheaton MG, Abramowitz JS, Franklin JC, Berman NC, Fabricant LE. Experiential avoidance and saving cognitions in the prediction of hoarding symptoms. Cogn Ther Res. 2011;35(6):511-6.

14. Twohig MP. A randomized clinical trial of acceptance and commitment therapy versus progressive relaxation training in the treatment of obsessive compulsive disorder [Dissertation].Reno: Univ. of Nevada; 2007.

15. Twohig MP, Hayes SC, Plumb JC, Pruitt LD, Collins AB, HazlettStevens $\mathrm{H}$, et al. A randomized clinical trial of acceptance and commitment therapy versus progressive relaxation training for obsessive-compulsive disorder. J Consult Clin Psychol. 2010;78(5):705-16.

16. Twohig MP, Hayes SC, Masuda A. Increasing willingness to experience obsessions: acceptance and commitment therapy as a treatment for obsessive-compulsive disorder. Behav Ther. 2006;37(1):3-13.

17. Izadi R, Asgari K, Neshatdust $\mathrm{H}$, Abedi M. The Effect of acceptance and commitment therapy on the frequency and severity of symptoms of obsessive compulsive disorder. Zahedan J Res Med
Sci. 2012;14(10):107-12.

18. Armstrong AB. Acceptance and commitment therapy for adolescent obsessive-compulsive disorder. [Dissertation].Logan: Utah State Univ; 2011.

19. American Psychiatric Association. Diagnostic and statistical man ual of mental disorders. 4th edWashington, DC: American Psychiatric Association; 2000.

20. Navara CS, First NL, Schatten G. Phenotypic variations among paternal centrosomes expressed within the zygote as disparate microtubule lengths and sperm aster organization: correlations between centrosome activity and developmental success. Proc Natl Acad Sci U S A. 1996;93(11):5384-8.

21. First MB, Gibbon M, Spitzer RL, Williams JBW, Benjamin LS. Structured clinical interview for DSM-IV® axis II personality disorders (SCID-II), interview and questionnaire.Washington, DC: American Psychiatric Association; 1997.

22. Zanarini MC, Skodol AE, Bender D, Dolan R, Sanislow C, Schaefer E, et al. The Collaborative Longitudinal Personality Disorders Study: reliability of axis I and II diagnoses. J Pers Disord. 2000;14(4):291-9.

23. Goodman WK, Price LH, Rasmussen SA, Mazure C, Fleischmann RL, Hill CL, et al. The Yale-Brown Obsessive Compulsive Scale. I. Development, use, and reliability. Arch Gen Psychiatry. 1989;46(11):1006-11.

24. Goodman WK, Price LH, Rasmussen SA, Mazure C, Delgado P, Heninger GR, et al. The Yale-Brown Obsessive Compulsive Scale. II. Validity. Arch Gen Psychiatry. 1989;46(11):1012-6.

25. Mccurry SM, Hayes SC, Strosahl K, Wilson KG, Bissett RT, Pistorello J, et al. Measuring experiential avoidance: A preliminary test of a working model. Psychol Rec . 2004;54:553-78.

26. Woody SR, Steketee G, Chambless DL. Reliability and validity of the Yale-Brown obsessive-compulsive scale. Behav Res Ther. 1995;33(5):597-605.

27. Taylor S. Assessment of obsessions and compulsions: Reliability, validity, and sensitivity to treatment effects. Clin Psychol Rev. 1995;15(4):261-96.

28. Aboory S, Mehrya AH, Ghareeb A. [Comparing the effectiveness of cognitive-behavioral techniques, clomipramine and their combination in the treatment of obserssive compulsive disorder] Iran J Psychiatry Clin Psychol. 1998;4(1):25-35.

29. Zargar F. Comparing the efficacy of acceptance-based behavior therapy to applied relaxation on female with generalized anxiety disorder [Dissertation].Tehran, Iran: Tehran Univ. Med Sci; 2011.

30. Bakhtiary M. Mental disorders in patients with body disorder [Dissertation].Tehran, Iran: Iran Univ Med Sci; 2000.

31. Sousa MB, Isolan LR, Oliveira RR, Manfro GG, Cordioli AV. A randomized clinical trial of cognitive-behavioral group therapy and sertraline in the treatment of obsessive-compulsive disorder. $J$ Clin Psychiatry. 2006;67(7):1133-9.

32. Cohen J. A power primer. Psychol Bull. 1992;112(1):155-9.

33. Foa EB, Liebowitz MR, Kozak MJ, Davies S, Campeas R, Franklin ME, et al. Randomized, placebo-controlled trial of exposure and ritual prevention, clomipramine, and their combination in the treatment of obsessive-compulsive disorder. Am J Psychiatry. 2005;162(1):151-61.

34. Abramowitz JS, Taylor S, McKay D. Obsessive-compulsive disorder. Lancet. 2009;374(9688):491-9.

35. Shareh H, Gharraee B, Atef-Vahid MK, Eftekhar M. Metacognitive therapy (MCT), fluvoxamine, and combined treatment in improving obsessive-compulsive, depressive and anxiety symptoms in patients with obsessive-compulsive disorder (OCD). Iran J Psychiatry Behav Sci. 2010;4(2):17-25.

36. Giasuddin NA, Nahar JS, Morshed NM, Balhara YP, Sobhan MA Efficacy of combination of fluoxetine and cognitive behavioral therapy and fluoxetine alone for the treatment of obsessive compulsive disorder. PakJ Pharm Sci. 2013;26(1):95-8.

37. Foa EB, Franklin ME, Moser J. Context in the clinic: how well do cognitive-behavioral therapies and medications work in combination? Biol Psychiatry. 2002;52(10):987-97.

38. Albert U, Brunatto C. Obsessive-compulsive disorder in adults: Efficacy of combined and sequential treatments. Clin Neuropsychiatry. 2009;6:83-93. 